\title{
O FAZER CIENTÍFICO FRENTE À PERSPECTIVA DA NÃO \\ NEUTRALIDADE
}

\author{
Cleonara Maria Schwartr
}

Patricia Veronesi Batista

\section{Resumo}

Neste ensaio propõe-se refletir sobre questões relativas à neutralidade e à não neutralidade das pesquisas científicas. Compartilha-se da concepção da não-neutralidade da ciência, buscando explicitar argumentos que justifiquem tal compreensão, implicações a serem evitadas, assim como possibilidades para o fazer científico. O estudo compreende uma pesquisa bibliográfica e analítica, fundamentado em contribuições teóricas de Stengers (2002), Maturana (2001) e Dalmaso (2014). Defende-se a necessidade de uma nova postura do pesquisador, ciente das possibilidades e das reponsabilidades da perspectiva da não neutralidade, o que pode conferir maior credibilidade à prática científica.

Palavras-chave: ciência neutra; ciência não neutra; postura do pesquisador.

\section{THE SCIENTIFIC EXERCISE FRONT THE PERSPECTIVE OF NON-} NEUTRALITY

\section{Abstract}

This essay proposes to reflect on issues related to the neutrality and non-neutrality of scientific research. It shares the conception of the non-neutrality of science, seeking to make explicit arguments that justify such understanding, implications to be avoided, as well as possibilities for doing scientific work. The study comprises a bibliographic and analytical research, based on theoretical contributions by Stengers (2002), Maturana (2001) and Dalmaso (2014). The researcher defends the need for a new posture, aware of the possibilities and responsibilities from the perspective of non-neutrality, which can give greater credibility to scientific practice.

Keywords: science neutral; non-neutral science; researcher's posture.

\section{EL HACER CIENTÍFICO FRENTE A LA PERSPECTIVA DE LA NO NEUTRALIDAD}

Resumen

Este ensayo propone reflexionar sobre temas relacionados con la neutralidad y no neutralidad de la investigación científica. Comparte la concepción de la no neutralidad de la ciencia, buscando hacer argumentos explícitos que justifiquen tal comprensión, las implicaciones a evitar, así como las posibilidades de hacer un trabajo científico. El estudio comprende una investigación bibliográfica y analítica, basada en los aportes teóricos de Stengers (2002), Maturana (2001) y Dalmaso (2014). El investigador defiende la necesidad de una nueva postura, consciente de las posibilidades y responsabilidades desde la perspectiva de la no neutralidad, que puede dar mayor credibilidad a la práctica científica.

Palabras clave: ciencia neutral; ciencia no neutral; postura del investigador. 


\section{SITUANDO O PROBLEMA PESQUISADO}

Há quem conceba a ciência como livre de interesses e de influências de qualquer ordem externa, como um conhecimento objetivo, independente de valores dos cientistas ou de ordem social e histórica, quer dizer, como uma atividade neutra, que busca desvendar a verdade sobre realidades e/ou fenômenos investigados. Em contrapartida, há concepções que refutam a possibilidade de neutralidade, defendendo a ausência de neutralidade da ciência frente às forças externas, propondo que a prática científica deve ser compreendida em sua complexidade. Assim, ao contrário da racionalidade científica, que tende a apontar para uma determinada forma de conceber e de desenvolver ciência, passa-se a considerar outras abordagens possíveis e a defender a neutralidade como um aspecto de difícil realização no atual contexto, no qual a ciência acaba por comprometer-se com o desenvolvimento tecnológico e econômico das nações, avaliando a tese da neutralidade como uma mera ilusão (OLIVEIRA, 2003).

Lacey (2000) nos apresenta que, segundo a perspectiva da neutralidade da ciência, um saber científico é, necessariamente, fundamentado em teorias de caráter empírico, podendo ser avaliado a partir de valores cognitivos, apontando para características desejáveis por tais teorias, como: adequação empírica, poder de explicação e consistência intertéorica. Defende-se que a ciência deve ser livre de valores não cognitivos ou, pelo menos, daqueles que não são propícios às investigações empíricas, que não possuem pressuposições favoráveis às avaliações racionalcientíficas, que não estão alinhados com o que Lacey (2000) chama de perspectiva moderna de controle, comprometida com "[...] o controle dos objetos naturais e com o avanço tecnológico, [...]" (LACEY, 2000, p. 2).

Esta perspectiva de ciência livre de valores não cognitivos pode ser também explicitada pelos pressupostos de imparcialidade (segundo o qual não há espaço, por exemplo, para valores morais ou sociais que não se sustentam em práticas científicas), neutralidade (dedicado a impedir a interferência de valores particulares e a permitir acesso às variadas opções de perspectivas viáveis de pesquisa) e autonomia (a partir do qual entende-se que a realização de pesquisas científicas deve ocorrer livremente, sem influências de valores sociais, morais, interesses e poderes externos), fundamentando assim, as práticas e as instituições reconhecidas como científicas (LACEY, 2000).

A fim de problematizar aspectos relacionados a imparcialidade, a neutralidade e a autonomia, Lacey (2000) lança a questão: a ciência é ou não é livre de valores? Questiona a adesão às estratégias materialistas ${ }^{1}$ que eliminam qualquer relação com aspectos sociais, humanos, ecológicos etc. desconsiderando as possibilidades de investigação não-materiais, o que acaba por direcionar a investigação científica, comprometendo, consequentemente, o pressuposto da autonomia. Da mesma forma, ocorre prejuízo de neutralidade quando se prioriza a imparcialidade, e exemplifica: “[...] a implementação, numa escala significativa, de uma agricultura informada biotecnologicamente tende a debilitar as condições para a agroecologia e vice versa [...]" (LACEY, 2000, p. 9).

\footnotetext{
${ }^{1}$ Denominada estratégia materialista de restrição e seleção pela filosofia da ciência de Lacey. Atende ao pressuposto de que o conhecimento científico deve se expressar valendo-se de teorias comprováveis, desta forma, restringe o tipo de teoria, seleciona objetos e fenômenos que mereçam ser investigados, define dados empíricos pertinentes para comprovar a teoria, corroborando para sua aceitabilidade, replicabilidade e representação em uma linguagem descritiva, quantitativa e matemática (SANTOS, 2004; OLIVEIRA, 2008).
} 
Percebe-se assim que ao optar por determinada teoria, considerada imparcial, criam-se obstáculos para uma postura efetivamente neutra e compromete-se a liberdade de acesso às variadas perspectivas viáveis. Logo, é importante perceber que há um jogo de forças em questão, e que ao priorizar determinados valores, outros acabam sendo, inevitavelmente, desconsiderados. Desta forma, vê-se que não é algo tão simples responder à pergunta lançada por Lacey (2000)

Pensando especificamente na perspectiva da neutralidade, compreende um aspecto que, historicamente, tem sido questionado, seja quando pensado no contexto da religião comprometida com dogmatismos; seja no contexto do pós-segunda guerra mundial - tendo em vista as consequências éticas das pesquisas científicas; seja mais recentemente, partindo de discussões sobre a necessidade de refletir o papel social da ciência - considerando as desigualdades sociais, a destruição do meio ambiente, os interesses econômicos etc.

Nesse ínterim, destacou-se, como divisor de águas, o contexto pós-segunda guerra mundial, a partir do qual tornou-se urgente pensar as implicações político-sociais da produção e da aplicação de conhecimentos científicos, pois já não havia possibilidade de tratar a ciência, suas criações letais e o envolvimento com propósitos políticos e econômicos, com a mesma ingenuidade de outrora. Em contrapartida, ganhou força naquele contexto a defesa da ciência neutra, como tática para delegar à sociedade o mal-uso que pode ser feito da ciência.

Neste trabalho, temos como motivação central compreender a pesquisa científica e suas implicações em maior complexidade, sem negar as contribuições dadas pela racionalidade científica, mas defendendo a necessidade de se ampliar as possibilidades de pesquisas, reconhecendo relações com aspectos tecnológicos, sociais, econômicos, ecológicos etc. e comprometendo-se com a necessidade de evidenciar tais implicações e de responsabilizar-se por elas enquanto pesquisadores/as. Deste modo, o ensaio é fruto de uma pesquisa bibliográfica e analítica $^{2}$, com intuito de refletir sobre qual deve ser a postura do/a pesquisador/a frente às forças implicadas em suas pesquisas?

\section{CAMINHOS TEÓRICOS}

Apontados os anseios da pesquisa, optamos, enquanto fundamento teórico, por guiar a discussão sob a ótica do que Stengers (2002) apresenta sobre a indissociabilidade entre ciência e política; do que Maturana (2001) problematiza acerca da autonomia; e do que Dalmaso (2014) coloca sobre a perspectiva da invenção.

Stengers (2002, p. 11) nos apresenta o emergir de ideias contrárias ao que chama de uma ciência pura (típico da tradição demarcacionista) no final do século XX, colocando em questão a tradicional separação entre ciência e sociedade, em função de críticas oriundas dos domínios da sociologia da ciência. A filósofa e historiadora das ciências, sem tomar partido diretamente de

\footnotetext{
2 As fontes foram selecionadas no Portal de Periódicos da Coordenação de Aperfeiçoamento de Pessoal de Nível Superior (Capes), na Biblioteca Digital Brasileira de Teses e Dissertações do Instituto Brasileiro de Informação em Ciência e Tecnologia (BDTD do Ibict) e no Google Acadêmico, lançando as expressões e as estratégia de busca que seguem: neutralidade da ciência OR ciência neutra. O objetivo foi recuperar documentos que apresentassem qualquer um dos referidos termos, em português, revisado por pares e da área de conhecimento Educação, conforme as possibilidades de cada base de dados. Em meio ao 514 recuperados no Portal de Periódicos da Capes, 14 foram selecionados; em meio aos 19 recuperados na BDTD do Ibict, cinco foram selecionados; em meio aos milhares recuperados no Google Acadêmico, cinco foram selecionados. Por fim, no total, oito fontes contribuíram, efetivamente, na construção do texto deste artigo.
} 
uma ou de outra perspectiva, busca explorar possibilidades do registro político para tratar das ciências, ou seja, relaciona ciência e política, considerando suas consequências, as relações de poder existentes entre ciência e interesses políticos, econômicos, sociais etc. pois, sem afirmar que a ciência se reduz a forças de poder, reconhece que nunca, no decorrer da história, esteve ilesa a elas, sendo a política inerente ao fazer científico, o que não faz da ciência menos pura, nem retira seu valor, mas evidencia que as perspectivas sociológica e da tradição epistemológica não bastam para pensar a ciência, seu alcance e suas implicações.

Assim, Stengers (2002) retrata que a ciência não se separa de questões políticoideológicas, não podendo ser pensada como sendo da ordem da neutralidade, pois sempre haverá relações de poder e de força implicadas, mesmo naquelas propostas dedicadas à imparcialidade ou que propõe autonomia da pesquisa e/ou do pesquisador frente ao objeto investigado. Acreditamos que ao negar essa realidade, acaba-se por limitar o alcance e o potencial transformativo das investigações, além de fragilizar o comprometimento do pesquisador frente aos seus direitos e deveres.

Essa relação paradoxal que propõe autonomia, mas acaba por limitar as abordagens, é tratada por Maturana (2001) em contexto semelhante, o da Educação Popular, no qual acreditava-se que a autonomia seria alcançada mediante a conscientização dos públicos populares, por meio do acesso às informações, aos conhecimentos, a um esclarecimento científico, o que proporcionaria uma visão crítica sobre a realidade. "Daí o entendimento de que 'conscientizar' seria um convite para a captação da verdade. Dessa compreensão advém a idéia de que a Educação Popular seria um esforço de capacitação científica e técnica dos grupos populares" (MATURANA, 2001, p. 3).

Contudo, pesquisas levantadas por Maturana (2001) apontam para dissonâncias entre o discurso e a prática da ação pedagógica, cultivando a dependência no lugar de uma postura ativa, pois faltou considerar meios para que os sujeitos em formação refletissem sobre si próprios e sobre o contexto do qual fazem parte, apostando-se em discursos homogeneizadores, saberes pré-concebidos, externos e desvinculados da conjuntura popular, como se fossem caminhos seguros e únicos para o alcance da autonomia.

Reconhecemos que existem diferenças entre o que Stengers (2002) e Maturana (2001) retratam, são abordagens distintas, em uma situação fala-se da produção de conhecimento e na outra fala-se do acesso ao conhecimento já produzido, avaliando o potencial transformativo sobre determinado público. Contudo, nos auxilia a perceber que o alcance das transformações sociais que almejamos depende da relação e do comprometimento que estabelecemos com o contexto sócio-histórico do qual fazemos parte, o qual também nos constitui.

Maturana (2001) vai nos dizer que a vida é conhecimento, e o conhecimento é fruto da forma como o indivíduo organiza suas relações com o externo. Mas o conhecimento não se organiza em função das exigências externas e sim das exigências internas, do próprio indivíduo. A organização autopoiética tem como referência a sua identidade autoproduzida, isto é, se realiza primeiramente pela sua capacidade de constituir significados próprios.

Dalmaso (2014), ao propor a perspectiva da invenção como uma nova forma de pensar os processos de aprendizagens, acaba por dialogar com o conceito de autopoiése de Maturana (2001), visto que propõe a problematização, a abertura, o indeterminismo e o inacabamento das operações cognitivas como caminho para que os sujeitos e o meio criem algo novo juntos. A problematização é vista como possibilidade para transformações, assim, fala-se menos em resolver problemas e mais em criar problemas, pois problematizar nos retira do lugar comum, faz 
com que algo se quebre, se desestabilize a nossa volta, nos levando a reflexões e a lugares até então desconhecidos.

Vemos na atualidade que o capitalismo individualiza e privatiza os problemas, considera o sujeito e sua experiência pessoal, mas não trata as pessoas mediante suas subjetividades, ou seja, não considera a experiência da época, de mundo, dentro e fora do sujeito, com todas as questões que os constituem. Entendemos que ao ampliar essas percepções, tem-se a possibilidade de um reposicionamento dos sujeitos no mundo, frente à coletividade, pois a história de cada um se constrói pela experiência pessoal e social.

Da mesma forma pensamos a relação da ciência com a sociedade e seus aspectos políticos, econômicos, sociais, culturais etc., afinal, não é possível separá-la do todo do qual faz parte, não sem repercutir em prejuízos, sem limitar o potencial transformativo das pesquisas científicas, sem comprometer o alcance de compreensões sobre a realidade, os direitos e os deveres dos cientistas.

\section{CIÊNCIA NÃO NEUTRA: IMPLICAÇÕES E POSSIBILIDADES}

Concebemos a não neutralidade da ciência desde o momento em que se escolhe um objeto de estudo, um problema a ser investigado, até as definições de métodos e recursos tecnológicos que serão utilizados. Nestas etapas, os cientistas, as agências de fomento, os governos, enfim, todos os sujeitos e organizações envolvidos, tomam decisões que priorizam determinadas abordagens em detrimento de outras. "Tais escolhas, com certeza, obedecem a interesses concretos, de caráter não exclusivamente cognitivo como pretenderia a alegada busca 'desinteressada' da verdade [...]" (SANTOS, 2004, p. 9).

Stengers (2002) evidencia que não se trata apenas de um movimento que leva a influências e trocas entre ciência e sociedade, existe uma real possibilidade de manipulação dos meios para alcançar determinados fins, exigindo atenção e comprometimento, tanto da comunidade científica, quanto da sociedade em geral.

Um aspecto que merece atenção especial é o desenvolvimento do conhecimento tecnológico (marcado por interesses políticos, econômicos, militares etc.) que direciona, significativamente, as ações da ciência na atualidade. Não há como negar que no decorrer da história humana as sociedades passaram por inúmeras transformações mediante as descobertas científicas e com o desenvolvimento mecânico, elétrico ou eletrônico, a ciência foi, paulatinamente, comprometendo-se com o desenvolvimento tecnológico, a ponto de caminharem lado a lado "[...] e hoje praticamente não se pode afirmar que a ciência seja uma atividade isolada e independente, menos ainda desinteressada (SANTOS, 2004, p. 74).

Pensando nas implicações de um olhar ingênuo frente ao fazer científico, concordamos com Rosa e Auler (2016, p. 204) quando afirmam que a concepção de neutralidade da ciência acaba por legitimar modelos decisórios tecnocráticos que comprometem processos participativos e democráticos e reduzem a participação da sociedade apenas ao papel de "usuária", que recebe ciência e tecnologia disponíveis, prontas e acabadas, cabendo apenas conferir bom uso, isto é, acaba por retirar a sociedade do planejamento da agenda de pesquisas e não permite apropriação crítica sobre o que é produzido.

Esse estado de alienação não nos parece razoável, permite retomar reflexão de Maturana (2001) sobre uma aparente autonomia, conferida, neste caso, à sociedade diante de todas as 
possibilidades que advêm das descobertas científicas e das inovações tecnológicas, mas que acabam limitando as oportunidades de avaliação, de participação e de interferência da sociedade nas questões científicas, impedindo sua atenção para o fato de que a ciência não deve ser vista como "[...] um processo progressivo, linear, perfeito e acabado de conhecimento, já que é uma construção humana inacabável, cheia de sobressaltos, sujeita a constantes mudanças de rumo [...]" (SANTOS, 2004, p. 18). Ou seja, como qualquer atividade humana, a ciência será sempre perpassada por influências, interesses e valores próprios de sua época, exigindo olhar cuidadoso, que uma vez assumido, por cientistas e pela sociedade em geral, pode conferir maior comprometimento e credibilidade ao fazer científico.

\section{O ETHOS CIENTÍFICO FRENTE À PERSPECTIVA DA NÃO NEUTRALIDADE}

As reflexões desenvolvidas neste estudo, evidenciam a necessidade de uma nova postura do/a pesquisador/a frente às forças implicadas em suas pesquisas, "[...] se antes se acreditava num ethos científico desinteressado, puro, seguro de si e de sua racionalidade, hoje, entretanto, são os interesses econômicos e políticos que conduzem a produção científica e tecnológica [...]" (SANTOS, 2004, p. 93). Desta forma, tendo em vista a não neutralidade da ciência, uma nova postura deve ser assumida, ciente das possibilidades e das reponsabilidades da perspectiva da não neutralidade, o que a nosso ver pode conferir maior credibilidade à prática científica.

Entendemos que o cientista, enquanto produtor de conhecimento, deve problematizar a história e suas implicações; deve, com honestidade, reconhecer que o conhecimento científico não se separa de questões político-ideológicas que perpassam a sociedade; e que a sociedade é, necessariamente, fonte de diferenças, não é constituída por dados acabados; logo, deve ter claro em mente qual deve ser o seu papel mediante a produção coletiva de conhecimentos, no contexto sócio-histórico do qual faz parte; e assim, refletir sobre os valores que estão sendo priorizados em suas pesquisas, sobre os valores que estão sendo silenciados e as consequências que procedem de ambos os enfoques.

Ao comprometer-se com a produção coletiva de conhecimentos, o pesquisador terá como pressuposto a pluralidade de ideias, as problematizações e as descobertas alcançadas individualmente, mas, sobretudo, coletivamente, valorizando assim, o compartilhamento de perspectivas, não almejando impor as suas descobertas como se fossem as únicas visões de mundo a serem consideradas, ao contrário, terá como um de seus objetivos permitir que as pessoas construam suas próprias compreensões a partir da troca, da diferença, da controvérsia, contribuindo com meios que proporcionem o emergir de significações próprias.

Concordamos com Rosa e Auler (2016, p. 205) quando afirmam ser imperativo "[...] superar a linearidade que vai da Ciência-Tecnologia (CT) para a sociedade (S) [...]", ou seja, é fundamental passarmos a "[...] avaliar impactos da sociedade, ou setores dessa, com seus valores particulares, no direcionamento dado ao desenvolvimento científico-tecnológico.” Da mesma forma, torna-se urgente repensar as políticas científico-tecnológicas, com o propósito de tê-las alinhadas às demandas sociais locais.

Vê-se que é preciso envolver a sociedade no planejamento de pesquisas, na pré-produção, ampliando oportunidades democráticas para que todos contribuam na agenda da ciência e tecnologia, não se limitando a apenas receber produtos e/ou resultados prontos. "Problematizar 
essa limitação coloca-se na perspectiva de potencializar, mediante processos educativos, mecanismos ampliados de participação [...]" (ROSA; AULER, 2016, p. 215).

Uma maior participação da sociedade poderia repercutir em posturas mais ativas, tendo em vista as oportunidades de refletir sobre si mesmos e sobre o meio em que estão inseridos, comprometidos com desafios e problemas próprios de seus contextos sócio-históricos, atentos às demandas que surgem da coletividade e da pluralidade de ideias. Nestes moldes, o conhecimento seria alcançado a partir das necessidades daquela sociedade, favorecendo o movimento autopoiético e a autonomia tratada por Maturana (2001).

A realidade muda quando as práticas mudam, sendo assim, o pesquisador deve estar aberto à problematização, à possibilidade de criar algo novo com o outro (que deve ser respeitado por ser um legítimo outro), processo este que tende a favorecer importantes mudanças sociais, além do próprio movimento de outramento, ou seja, de tornar-se outro, ao qual os sujeitos envolvidos serão, inevitavelmente, expostos.

Por conseguinte, tem-se oportunidades coletivas de invenção, perspectiva apresentada por Dalmaso (2014) como estratégia que permite o acoplamento dos sujeitos à sua realidade sóciohistórica, por meio da qual os sujeitos se constituem, trocam, criam juntos e se deixam afetar, transformando a si próprios e à realidade externa. Rompe-se assim com os modelos prédeterminados, passando a considerar os sujeitos, suas experiências pessoais e sociais, ampliandose as percepções sobre qualquer que seja o objeto investigado, permitindo o constante reposicionamento perante as demandas e as transformações que emergem de seus contextos de pesquisa.

\section{REFERÊNCIAS}

DALMASO, Alice Copetti. A perspectiva da invenção numa pesquisa em educação: processos e aprendizagens de um pesquisar-inventivo. Revista Digital do LAV, v. 7, n. 2, p. 005-029, 2014. Disponível em: https://periodicos.ufsm.br/index.php/revislav/article/view/15113. Acesso em: 30 jun. 2019.

LACEY, Hugh. As formas nas quais as ciências são e não são livres de valores. Crítica, v. 6, n. 21, p. 2000.111 - Disponível em: http://www.uel.br/pessoal/mrs/pages/arquivos/lacey.critica.2000.pdf. Acesso em: 30 jun. 2019. MATURANA, Humberto. Desfaz̧endo nós: Educação e Autopoiése. 2001. Disponível em: http://23reuniao.anped.org.br/textos/0604t.PDF. Acesso em: 30 jun. 2019.

OLIVEIRA, Marcos Barbosa de. Considerações sobre a neutralidade da ciência. Transformação: Revista de Filosofia, v. 26, n. 1, 2003. Disponível em: http://revistas.marilia.unesp.br/index.php/transformacao/article/view/852. Acesso em: 30 jun. 2019.

OLIVEIRA, Marcos Barbosa de. Neutralidade da ciência, desencantamento do mundo e controle da natureza. Scientice studia, v. 6, n. 1, p. 97-116, 2008. Disponível em: http://www.scielo.br/scielo.php?pid=S1678-31662008000100005\&script=sci arttext\&tlng=pt. Acesso em: 30 jun. 2019.

ROSA, Suiane Ewerling; AULER, Décio. Não neutralidade da ciência-tecnologia: problematizando silenciamentos em práticas educativas CTS. Alexandria: Revista de Educação em Ciência e Tecnologia, v. 9, n. 2, p. 203-231, 2016. Disponível em: 
https://periodicos.ufsc.br/index.php/alexandria/article/view/1982-5153.2016v9n2p203. Acesso em: 30 jun. 2019.

SANTOS, Paulo Roberto dos. A questão da neutralidade: um debate necessário no ensino de ciências. 2004. 128 f. Dissertação (Mestrado em Educação) - Pós-Graduação da Faculdade de Educação, Universidade de São Paulo, São Paulo, 2004. Disponível em: http://bdtd.ibict.br/vufind/Record/USP 5af05228c973cab800422f88674711b7. Acesso em: 30 jun. 2019.

STENGERS, Isabelle. A invenção das ciências modernas. São Paulo: Editora 34, 2002.

Submetido em novembro de 2020 Aprovado em junho de 2021

\section{Informações do(a)(s) autor(a)(es)}

Cleonara Maria Schwartz

Universidade Federal do Espírito Santo

E-mail: cleonara.schwartz@ufes.br

ORCID: http://orcid.org/0000-0003-4411-2234

Link Lattes: http://lattes.cnpq.br/1768605311310158

Patrícia Veronesi Batista

Prefeitura Municipal de Vila Velha

E-mail: veronesi.pb@gmail.com

ORCID: http://orcid.org/0000-0002-3774-4519

Link Lattes: http://lattes.cnpq.br/8409349881650090 